\title{
What happens to the husband's retirement decision when the wife's retirement incentives change?
}

\author{
Håkan Selin ${ }^{1,2}$
}

Published online: 19 October 2016

(C) The Author(s) 2016. This article is published with open access at Springerlink.com

\begin{abstract}
In this paper, I exploit population-wide administrative data and a Swedish occupational pension reform, which primarily affected a subgroup of female workers, to recover the effect of the wife's retirement incentive on the husband's retirement behavior. I estimate a sharp relative decrease in the retirement probability of 63-yearold wives who were treated by the reform. However, there was no significant response of their husbands, and this finding is surprisingly robust. This suggests that crosseffects (from the wife to the husband) are substantially smaller than the direct effects of the wife's own incentive on the wife's retirement.
\end{abstract}

Keywords Joint retirement $\cdot$ Retirement age $\cdot$ Occupational pensions

JEL Classification H55 $\cdot \mathrm{J} 13 \cdot \mathrm{J} 21$

\section{Introduction}

Several studies (e.g., Hurd 1990; An et al. 2004; Schirle 2008) document a strong correlation in spouses' retirement behavior. However, considerably less is known about the causal impact of one spouse's retirement incentive on the other spouse's retirement. Suppose that the wife's pension benefit accrual increases. If the substitution effect dominates, the wife works longer. But to what extent is the husband's labor supply affected? This is a key issue in policy design. If complementarities in leisure are

\åkan Selin

hakan.selin@ifau.uu.se

1 Institute for Evaluation of Labour Market and Education Policy (IFAU), 75120 Uppsala, Sweden

2 Uppsala Center for Fiscal Studies at the Department of Economics, Uppsala University, Uppsala, Sweden 
important, a delayed retirement age of female workers potentially leads to an aggregate increase in labor force participation rates of elderly males.

In this paper, I exploit a pension reform, which primarily affected a subgroup of female workers, to recover the effect of the wife's retirement incentive on the husband's retirement behavior. Before 2001, broad categories of Swedish local government workers in female-dominated occupations were entitled to retire with full pension benefits already at the age of 63. This possibility was abolished for those turning 63 in 2001. At the same time, there were no major changes in the private sector occupational pension plans. This enables me to compare couples in eligible and ineligible cohorts where the wife prior to retirement was a local government employee and private sector employee, respectively. Hence, spillover effects can be examined in a transparent way using graphical evidence and administrative data containing the entire Swedish population.

In a difference-in-difference setup, I estimate a sharp relative decrease in the retirement probability of 63-year-old wives in the local government sector in the years following the reform. Seen over the whole post-reform period 2001-2005, the relative decrease amounts to around 20 percentage points as compared to the pre-reform year 2000. This significant own response is consistent with earlier studies (e.g., Karlström et al. 2011). However, there was no significant response of their husbands, and this finding is surprisingly robust. In the most preferred model, which includes a full set of control variables, the point estimate of the treatment effect is 0.007 . The $95 \%$ confidence interval ranges from -0.028 to 0.041 . Accordingly, large cross-responses for husbands can be ruled out. This suggests that cross-effects (from wife to husband) are substantially smaller than the direct effect of the wife's own incentive on the wife's retirement. One potential explanation is that there was a strong norm of private sector workers to retire at 65 in Sweden. Such a strong norm might attenuate the husbands' cross-response.

A couple of things are worth pointing out, however. First, the results presented in this paper are still consistent with small cross-responses between spouses; the upper limit of the $95 \%$ confidence interval for the female response is -0.157 and the corresponding lower limit for the husbands' response is -0.028 . Thus, cross-effects of approximately $1 / 5$ of the wives' response cannot be ruled out.

Second, the reform used for identification affected wives' retirement behavior at age 63. This raises some issues concerning external validity. On average husbands tend to be older than their wives. Consequently, a large number husbands married to wives treated by the reform were aged 65 and above and retired and, hence, not in the estimation sample. In practice, the couples studied in this paper are couples where the age difference is small or where the husbands are younger than their wives. This is a very interesting population, but admittedly not fully representative.

Third, the data source used in this paper entails only a limited number of pre-reform years. Ideally, one would have liked to verify the common trend assumption in an even better way. A final caveat is therefore that the causal interpretation of the estimated parameters should be made with some caution. Still, the analysis is arguably more transparent and compelling than earlier studies.

The structure of this paper is as follows. Section 2 briefly discusses the previous literature. Section 3 contains an informal discussion about the theoretical framework. 
The Swedish occupational pension system, which provides the source of exogenous variation exploited in the paper, is described in Sect. 4. In Sect. 5 I discuss the empirical specification. Section 6 provides a description of the data source and a descriptive analysis. Section 7 reports the regression results, and Sect. 8 concludes the paper.

\section{Previous literature}

Most papers on retirement behavior abstract from the interaction between spouses. As discussed by Hurd (1990) a plausible reason for the historical neglect of the joint nature of retirement decisions is that female labor force participation historically has been low in most industrialized countries. Even though the literature has been growing in the last two decades it is still small. A majority of papers on the topic do not use reforms for identification. Important contributions along these lines are Blau (1998), Mastrogiacomo et al. (2004), Zweimüller et al. (1996), Coile (2004), Gustman and Steinmeier (2000, 2004) and Harnæs et al. (2006).

Several earlier papers examining the interdependence between spouses' retirement decisions (e.g., Coile 2004; Kapur and Rogowski 2007; Stancanelli 2012; Zweimüller et al. 1996) found an asymmetry in the way spouses react to each other's incentives: husbands are sensitive to changes in their wives' incentives but the opposite does not hold true. In particular, Coile (2004) estimated the spillover effects of the wives' retirement incentives on the husbands' retirement behavior to be approximately as large as the direct effect of the women's incentives on women's retirement. In contrast, using a very different methodology, Blau (1998) found strong associations between the labor force transition probabilities of one spouse and the labor force status of the other spouse, but that the pattern could not be explained by financial incentives.

A general challenge in the literature is to separate incentive effects from other factors affecting retirement decisions. Individuals with correlated unobserved tastes for leisure are likely to marry each other. It is likely, in turn, that individuals with strong unobserved preferences for leisure sort into pension schemes with certain characteristics. Moreover, pension incentives are typically functions of a set of observed personal characteristics that are plausibly also having direct effects on the husband's retirement decision. Suppose, for simplicity, that the wife's retirement incentive is a function of her age in a nonlinear way. In many settings, it would be difficult to control for the direct impact of the wife's age on the husband's retirement in a flexible way without also destroying the identification.

To overcome selection issues a small quasi-experimental literature, which exploits policy reforms, has emerged in recent years. ${ }^{1}$ Both Atalay and Barrett (2015) and Cribb et al. (2013) used cohort variation to assess the effect of changes in the wife's work incentives on the husband's retirement. Atalay and Barrett (2015) found that an increase in the pension eligibility age for women in Australia, which implied a reduction in pension wealth, led to an increase in the labor force participation of

\footnotetext{
1 Baker (2002) studied the interactions of spouses in a quasi-experimental setup; the introduction of the Spouse's Allowance (SPA) to the Canadian Income Security system in 1975. He found responsiveness both of husbands and wives. Due to the nature of the SPA reform Baker could not, however, disentangle the own incentive effect and the cross-incentive effect.
} 
married men. Interestingly, they also found that husbands who are older than their wives responded more strongly.

Cribb et al. (2013) evaluated the increase in the state pension age for women (i.e., the earliest age at which a woman can claim pension benefits) in the UK. When examining the increase from 60 to 61 (occurring in 2010), the authors both estimate a large direct effect on female employment and significant spillover effects on the husband's labor supply. An important difference between my study and the papers by Atalay and Barrett (2015) and Cribb et al. (2013) is that the latter papers use cohort variation whereas I exploit variation both within and between cohorts. $^{2}$

\section{Conceptual framework}

The analysis of this paper will be interpreted through the lens of a unitary family model of lifetime labor supply. Under some assumptions, the individual's lifetime labor supply problem can be represented as maximizing lifetime utility subject to a lifetime budget constraint, see e.g., Burtless (1986) and Brown (2013). In a unitary model, where the two spouses pool their wealth for consumption and simultaneously decide how many years to work, the slopes of the two-dimensional lifetime family budget constraint are given by the net rewards to working one additional year for each spouse. The net reward to working consists of the net wage plus the benefit accrual net of foregone benefits. ${ }^{3}$

Consider a pension reform which ceteris paribus increases the benefit accrual rate of one spouse. In general, this reform will induce (i) a wealth effect for both spouses, (ii) a substitution effect of the directly affected spouse and (iii) a cross-response from the other spouse. As will be further described below, the reform studied in this paper was unlikely to induce a wealth effect since pension wealth earned up to the date of the reform was unaffected. Hence, I will interpret the estimated treatment effect parameters as own substitution effects and cross-substitution effects.

There are, of course, alternative ways of modeling interactions of spouses. Bargaining models can either be cooperative [see Vermeulen (2002), for a survey and Michaud and Vermeulen (2011), for a recent application in this context] or noncooperative (e.g., Gustman and Steinmeier 2000, 2004). In bargaining models, an increase in the benefit accrual of the wife would not only affect the husband through the complementarity effect and the wealth effect but it would possibly also change the relative bargaining power between spouses. It should be emphasized that the reduced form empirical analysis of this paper will be insufficient to discriminate between different models of family decision making. I will simply be able to recover the net effect of a change in the wife's incentives on the husband's retirement.

\footnotetext{
2 Yet another identification strategy was suggested by Johnsen and Vaage (2015), who used an early retirement reform in Norway to analyze how one spouse's retirement affects the labor market behavior of the other spouse. In contrast to my paper-and the papers by Atalay and Barrett and Cribb et al._-Johnsen and Vaage examined a reduction of the retirement age affecting workers employed in firms covered by a voluntary early retirement scheme (from 67 to 62). The authors found that wives responded to husbands' early retirement decisions. Consistent with the results in this paper, there is less evidence of spillover effects going in the opposite direction (from wives to husbands).

3 A formal exposition of the model can be provided upon request.
} 


\section{Occupational pension reform}

\subsection{General description of occupational pensions}

In general, Swedish retirees obtain most of their pension income from the public pension system, which is financed by payroll taxes. However, the occupational pension system is a crucial complement. In contrast to the USA, where the characteristics of employer-sponsored 401 (k)-plans differ between firms, the rules governing the Swedish occupational pension system are quite uniform within a small number of large sectors of the labor market. The pension plans are determined by collective agreements that have been signed by the unions and the employers' associations. Both the Swedish occupational pension system and the public pension system are individual-based. Thus, the stream of pension benefits received upon retirement is independent of the earnings history of the spouse.

An overwhelming majority of Swedish employees (around 90\%) are covered by collective agreements. There are four main occupational pension schemes: one for blue-collar private sector workers, one for white-collar private sector workers, one for local government employees and one for central government employees. I will focus on the reform in the scheme for local government workers that occurred around the turn of the millennium. During the period of study, i.e., 1999-2005, there were no major changes in the private sector collective agreements.

\subsection{The occupational pension reform for local government workers}

The pre-reform agreement, PA-KL, which covered local government workers born before January 1, 1938, implied a so-called gross pension system. This means that the sum of the annual pension benefit from the public pension system and the annual benefit from the occupational pension system amounted to a certain fraction of the individual's qualifying income. The latter was determined by the occupational pension agreement. For a 63-year-old local government female full time employee with an average wage rate, born 1937 who retired in year 2000, the gross replacement rate was around $73 \%$. Suppose she was eligible for annual benefits from the public pension system of $60 \%$ of her qualifying income. Then her annual occupational pension benefit amounted to $13 \%$ of her qualifying income; the occupational benefit was the residual amount. Hence, the early-withdrawal penalties in the public pension system were irrelevant for those covered by the old collective agreement for local government workers. Rather, from the employee's perspective it was sufficient to know about the gross replacement rate.

Under the pre-reform DB plan, different occupational categories in the local public sector faced different retirement ages. The "retirement age" could either be defined as a specific point in time (the month the employee turned 65) or an interval, 63-to65. At the lower end of the age interval, the employee was entitled to full retirement benefits given that he/she fulfilled the other criteria for eligibility. At the upper end of the time interval, the employee was obliged to retire unless the employer offered a prolongation. Early withdrawals before the retirement age could be made from the 
age of 60 under the PA-KL agreement. Early retirement was subject to a penalty, i.e., a reduction in the gross replacement rate (see Appendix 3).

Broad categories of female local government workers faced the 63-to-65 rule, for example most occupational categories belonging to the Swedish Municipal Workers' Union (Kommunalarbetareförbundet). ${ }^{4}$ Large occupational groups organized by the union include assistant nurses, child minders and cleaners. Other female-dominated occupational categories like hospital nurses and pre-school teachers also had the opportunity of retiring with full pension at the age of 63 .

In 1998, a new agreement, PFA98, was signed for Swedish local government employees born after January $1,1938 .^{5}$ The new PFA98 agreement came into effect on January 1, 2000 for those born in 1938 and later. The first cohort of 63-year-olds to earn pension benefits from the new system turned 63 in 2001. Those born in 1937 and earlier were completely unaffected by the occupational reform. The implementation of PFA98 marked a move away from a DB to a funded defined contribution (DC) system. In the new system, the employer paid pension contributions as a certain percentage $(3.4 \%)$ of gross wages up to a ceiling. ${ }^{6}$ Accordingly, in the new system, the employee always increased her pension wealth by postponing retirement.

The media coverage in 1998 was poor, and it is difficult to find explicit motives of the reform. ${ }^{7}$ However, it is obvious that the change was part of a general trend in favor of DC systems. The reform was also well aligned with the reform in the public pension system, see Sect. 4.3 below, which also affected individuals born in 1938 and onwards. Remember that the pension benefits from PA-KL interacted with the old public pension system. Hence, when the public pension system changed, it was natural to reform the occupational pension system of local government workers as well.

Owing to a transitional rule, the reform did not change the stock of already accumulated occupational pension wealth. From the age of 65, local government employees were entitled to a life annuity that was a function of the individual's employment history up to December 31, 1997. It corresponded to the annual pension benefit that the individual hypothetically received if she had retired by December 31, 1997. Since older workers ceteris paribus accrued more pension wealth up to December 31, 1997, than younger workers, the importance of the transitional rule was declining in birth year. Viewed from the perspective of the life cycle model discussed in Sect. 3, the transitional rule is important: it implies that the return to inframarginal years of work up to 1998 was unchanged by the reform. Hence, wealth effects will be less important as compared to a situation where the stock of pension wealth also had changed.

\footnotetext{
4 Swedish Municipal Workers' Union is a large Swedish union for blue-collar workers mainly in the local government sector. More than $80 \%$ of the members are females.

5 Glans (2009) was the first paper to exploit this occupational reform. After the first working paper version of my paper, Selin (2011), the same reform has been analyzed by Gerard and Nekby (2012) and Hagen (2016).

${ }^{6}$ For wages above the ceiling of 7.5 increased price base amounts, a DB system was retained. This cap roughly coincided with the ceiling of the public pension system. Above the ceiling, the employer still made a small DC contribution (1.0\%).

7 A search in the virtual press archive "Presstext," which covers the largest daily newspapers in Sweden, reveals that the first article mentioning "PFA98" is written in the fall of year 2000.
} 


\subsection{The public pension system and private sector pensions}

Those born in 1938 were also the first birth cohort to be exposed to the new Swedish public pension system, "the notional DC system," which has been described by, e.g., Sundén (2006). In the new Swedish pension system, the pension benefit is a function of lifetime income, and the pension benefits are indexed with income growth rather than inflation, which was the case in the old system. The nationwide reform affected all individuals born after 1937 included in the empirical analysis. The new public pension system was phased in gradually. Those who were born in 1938 received 4/5 of their benefits from the old system and 1/5 from the new one. Each cohort then increased its share of benefits from the new system by $1 / 20$. Benefits from the new system were distributed for the first time in $2001 .^{8}$

There are two occupational pension systems in the private sector; one for blue-collar workers and one for white-collar workers. Crucially, there were no major changes in these collective agreements during the period of study. Blue-collar workers were subject to a pure DC system; the contribution rate was $3.5 \%$ of the wage income. White-collar workers, on the other hand, faced a DB system, which guaranteed the employee $10 \%$ of the wage income in pension benefits up to the ceiling of the public pension system. Over the ceiling, the compensation rate was $65 \%$ up to a fairly large limit. To receive full occupational pension, the white-collar worker could not claim benefits before age 65 .

\subsection{Benefit accruals}

The data do not allow me to calculate pension incentive measures for the individuals in the sample. Instead, I calculate pension incentives for stylized typical cases. In Table 1, I report pension benefit accrual net of foregone benefits (BA) for individuals in the local government sector and in the private sector. I calculate benefits for two income levels: medium and high income. "Medium income" corresponds to median earnings at age 62 in year 2000 for men and women in the estimation sample. "High income" corresponds to the 90th percentile in the same sample. ${ }^{9}$ For local sector workers, I assume that the individual with medium (high) income is subject to the 63-to-65 rule (retirement age at 65) before the reform. For private sector workers, I assume that the individual with medium (high) income is a blue-collar worker (white-collar worker). The calculations are stylized and incorporate essential features of both the public and the occupational pension systems, such as early-withdrawal penalties, DC contributions and DB replacement rates.

Table 1 shows that there was an enormous increase in the BA at age 63 for a local government worker who was subject to the 63-to-65 rule. For the 1937 cohort, the BA was strongly negative: if the individual chose to work an additional year at age 63 , she

\footnotetext{
8 At a general level, it has proven difficult to empirically evaluate the large-scale Swedish pension reform on labor market outcomes and savings. Due to the gradual phase-in of the new pension system the differences in financial incentives between adjacent cohorts are relatively small. This has led researchers to use simulation methods to evaluate employment responses to the public pension reform (Laun and Wallenius 2015).

9 The median is 5.3 price base amounts and the 90 th percentile is 9.2 price base amounts.
} 
Table 1 Pension benefit accruals net of foregone benefits, expressed as a fraction of wage income

\begin{tabular}{llll}
\hline & Birth cohort 1937 & Birth cohort 1942 & Difference \\
\hline Age & Medium—LocGov & Medium—LocGov & \\
61 & 0.026 & 0.154 & 0.128 \\
62 & -0.176 & 0.120 & 0.295 \\
63 & -0.712 & 0.080 & 0.792 \\
Age & High—LocGov & High-LocGov & \\
61 & 0.152 & 0.133 & -0.019 \\
62 & -0.045 & 0.095 & 0.141 \\
63 & -0.227 & 0.056 & 0.283 \\
Age & Medium—Private & Medium—Private & \\
61 & 0.272 & 0.270 & -0.002 \\
62 & 0.155 & 0.120 & -0.035 \\
63 & 0.100 & 0.081 & -0.019 \\
Age & High-Private & High-Private & \\
61 & 0.266 & 0.223 & -0.043 \\
62 & 0.202 & 0.176 & -0.026 \\
63 & 0.136 & 0.125 & -0.012 \\
\hline
\end{tabular}

The benefit accrual of age $s$ is the difference in pension wealth from claiming retirement benefits directly after turning $s$ years old and directly after turning $s+1$ years old. The stock of pension wealth has been discounted back to age $s-1$. The discount rate is set to $3 \%$. Individuals are assumed to live until the age of 86. Individuals are assumed to earn a constant real wage since the age of 65 . Both historical and future real income growth is set to $1.6 \%$. "Medium" ("High") refers to earnings in the 50th (90th) percentile of the estimation sample in 2000 (men and women pooled)

lost benefits amounting to $71 \%$ of the current wage after discounting. For the 1942 cohort, the BA was positive at age 63 . We also see that a high-income individual in the local government sector (who pre-reform was subject to a retirement age of 65) was affected by the reform. The reason is that the pre-reform early-withdrawal penalty was quite low. Notably, the changes in BA in the private sector were considerably more modest, for both blue- and white-collar workers. Their occupational pensions stayed the same. Accordingly, the changes in the private sector emanate from the reform in the public pension system; those born in 1942 received 8/20 of their pension benefits from the new system. Since pension benefits in the new system are indexed with an income index, the BA depends on assumptions about income growth. Here, I assume that future real income growth is equal to average real annual income growth 19602016 , namely $1.6 \%$. Under this very reasonable assumption, not much happens to the $\mathrm{BA}$ in the private sector.

\section{Empirical model}

The idea of this paper is to estimate the effect of the pension reform on the husbands' behavior. All husbands and wives included in the analysis belonged to the 
labor force the preceding year, i.e., they received no pension income and reported positive earnings. The "treatment group" consists of husbands married to female local government sector workers who were 63 years of age and who were exposed to the new DC plan. The "control group" consists of men married to 63-year-old female private sector workers who were not exposed to the occupational pension reform in the local government sector. In the next section, I will further discuss the definitions of these concepts. The 1938 cohort of female local government workersthe first cohort to be exposed to the new DC plan-turned 63 in 2001. In the baseline model, 2000 is the pre-reform year and 2001-2005 are the post-reform years.

The relevant difference-in-difference regression equation reads

$$
\begin{aligned}
y_{i g t}= & \sum_{t=2001}^{2005} \beta_{t}\left(\mathrm{LGW}_{g} \times \mathrm{YEAR}_{t}\right)+\theta_{\mathrm{LGW}} \mathrm{LGW}_{g} \\
& +\sum_{t=2001}^{2005} \varsigma_{t} \mathrm{YEAR}_{t}+\delta X_{i g t}+\varepsilon_{i g t}
\end{aligned}
$$

for all $i$ in couples where both spouses belonged to the labor force in the year $t-1$. $i$ is an individual index, $t$ is a time index and $g$ indexes the occupational sector of the wife (either local government or private sector). $y_{i g t}$ is an indicator variable that takes the value of 1 if the husband/wife retires in year $t$. $\mathrm{LGW}_{g}$ is an indicator that is 1 if the wife was employed in the local government sector in year $t-1$. $\mathrm{YEAR}_{t}$ is a year $t$-specific fixed effect. $X_{i g t}$ is a vector of family characteristics that also includes a constant term. $\varepsilon_{i g t}$, finally, is an error term. Equation (1) will be estimated as a linear probability model. The key estimated interaction terms are similar if a probit model is used and interaction effects are calculated in the way proposed by $\mathrm{Ai}$ and Norton (2003).

We observe the assignment into treatment and control groups. However, as we describe below in Sect. 6.1 we do not observe the treatment intensity as eligibility for the 63-to-65 rule is unobserved. Hence, $\beta_{t}$ of Eq. (1) should be interpreted as intention-to-treat (ITT) parameters.

One might expect the treatment effects to be heterogeneous for the years 20012005. For instance, if norms adjust slowly in response to the new pension plan, one can expect a delayed response of the treated wives and, consequently, a delayed response of husbands. Therefore, I also report estimates of the treatment effect for each specific year. The crucial identifying assumption is that the outcome variable evolved in the same way in the treated group (husbands married to wives in the local government sector) as in the non-treated group (husbands married to wives in the private sector) in the absence of a pension plan reform. Below, in Sect. 7.3, I will further discuss (and test) the identifying assumption. 


\section{Data issues}

\subsection{Data source, sample selection and variables}

This study exploits a administrative data source which covers the total Swedish population for the years 1998-2005. ${ }^{10}$ Crucially, since there is an identifier for the household, I observe married couples. Furthermore, a number of demographic characteristics are included in the data. As already mentioned, the population of interest in this study is men married to women aged 63. Since lagged information is used to select the relevant samples, I can use the years 1999-2005 in the analysis. In total, there are 193,391 couples in the data 1999-2005 where the wife is aged 63. Crucially, the population is conditioned on both spouses being part of the labor force in the preceding year. It was necessary to impose such a constraint since information on sector affiliation was only available in the data for those actually working. I also perform robustness checks where I condition the sample on both spouses being in the labor force in $t-2$.

Labor force participation is defined as having positive labor earnings and no pension income. Since the majority of 63-year-old women are married to older men who receive pension income, this restriction reduces the sample size considerably to 26,131 couples. Some additional exclusions were made. First, I excluded husbands who were employed in the local government sector, as these husbands might be subject to the occupational pension reform. Second, I also omitted couples where either the husband or the wife was affiliated with the central government sector. This was done since a new collective agreement, which affected retirement incentives, came into place during the period of study (2003) in this sector. ${ }^{11}$ These exclusions further reduced the sample to 17,626 couples. After having excluded a small number of observations with missing values on any of the key variables, the final regression sample contains 17,431 observations (1913 of those are used in the placebo analysis).

Importantly, there is information on sector affiliation for all years. From the sector affiliation code, it is possible to observe whether the individual is employed in the local government sector, the central government sector or in the private sector. ${ }^{12}$ Unfortunately, due to the complexity of the collective agreements I cannot observe if the local government worker was subject to the 63-to-65 rule. Thus, the treatment group also includes some couples where the wives faced a retirement age of 65 in the pre-reform system. However, all local government employees born after January 1, 1938, went from a DB to a DC plan regardless of retirement age.

The main advantage of administrative data-as compared to smaller self-reported survey data sets-is that some types of measurement errors are, in principle, absent

\footnotetext{
10 The data set was ordered from Statistics Sweden for the purpose of studying issues related to retirement savings.

11 The 2003 reform in the central government sector, which was also a move from a DB to a DC system, affected employees born in 1943 and after. However, due to transitional rules there is no sharp discontinuity. The new system was introduced smoothly and is fully phased in for the 1973 cohort. The main results of the paper are robust to including central government men and women in the control group.

12 There is not much switching across sectors. Of local government workers in the estimation sample, $98 \%$ were local government workers both in $t-1$ and $t-2$. Of local government workers in $2005,93 \%$ were local government workers both in $t-1$ and $t-7$.
} 
and that the entire population can be studied. On the other hand, as discussed by e.g. Hallberg (2011), a disadvantage in the context of studying retirement is that the tax registers provide data on a yearly, rather than monthly, basis. Hence, we typically observe pension income and earnings, but it is not possible to tell whether the individual has been retired on a part time basis or on a full time basis for a shorter period of time. In the data, the age variable is defined based on the age of the individual as of December 31. Accordingly, some of the 63-year-olds have been aged 62 during 11 months of the year and been facing marginal pension incentives applying to 62-year-olds.

In the baseline analysis, I define the indicator for retirement in the following nonarbitrary way: Individuals who receive a positive amount of pension income will be classified as retired. ${ }^{13}$ An advantage of this retirement definition is that someone who stops working and starts collecting pension benefits late in the year will be correctly classified as retired. The different collective agreements contained rules that prevented workers and/or made it unattractive for workers to work and receive pension benefits at the same time. ${ }^{14}$ However, an earnings-based retirement definition will be used as a robustness check, see Sect. 7.4.

The dummy variable for being a local government employee is defined based on information from the preceding year. I also divide the studied population into six educational categories and define dummies for the educational level based on those. Finally, I also construct 21 dummy variables for the county of residence.

\subsection{Graphical analysis}

Figure 1 depicts the distribution of husbands' ages. Figure 1a shows this distribution in the estimation sample. Remember that the estimation sample has been selected based on the criterion that both spouses were part of the labor force in the preceding year. Since there is a dramatic increase in pension benefit withdrawals among 65-year-olds, there is a huge hole in the distribution starting at age 66. Therefore, it can be interesting to look at a sample where the restriction that the husband must be in the labor force in year $t-1$ is dropped, but all other selection criteria are the same. In this sample (shown in Fig. 1b), the mean age difference between husbands and wives is 2.9 years. This is in line with the well-known empirical regularity that husbands typically are older than their wives. In the estimation sample, on the other hand, the mean age difference is -0.89 . This should be kept in mind when interpreting the estimated model parameters.

\footnotetext{
13 Individuals who received a disability pension can also be subsumed under this retirement concept prior to 2003. Disability pension income was classified as sickness insurance benefits (labor income) from 2003 and onwards, but as pension income prior to 2003. Probably for that reason, there is a large increase in labor income in 2003 and a decrease in pension income that year.

14 Occupational pension in the local government sector was subject to an earnings test. The main rule in the old PA-KL plan was that benefits decreased at a rate of $100 \%$ in the benefit recipient's earnings. In the post-reform PFA98 plan, the reduction rate was $73.5 \%$. However, the benefit recipient could get special provisions to work under both plans. Moreover, white-collar private workers aged below 65 were not allowed to withdraw pension benefits if they worked more than $8 \mathrm{~h}$ per week. There were no such restrictions for blue-collar private workers. However, once a blue-collar worker started to receive DC benefits, he could not accumulate any new DC wealth. Under both these two latter schemes, individuals were allowed to withdraw benefits from the age of 55 .
} 

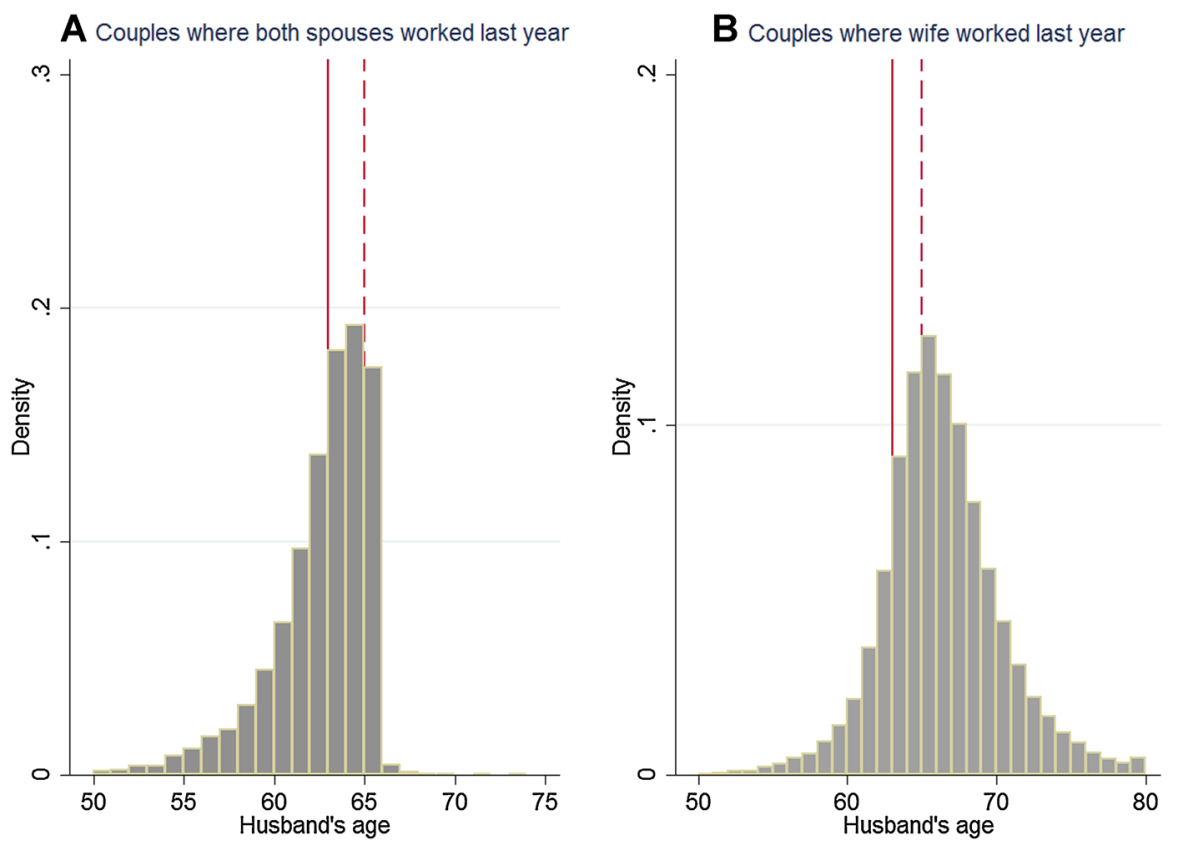

Fig. 1 Age distribution of husbands married to wives aged 63 in the estimation sample. The left (solid) line depicts the wife's age (63) and the right (dashed) line depicts the normal retirement age (65)

Figure 2a illustrates the probability of retiring for married females, conditional on being in the labor force in the preceding year. Among the 63-year-olds in 2000, which was the last cohort to be exposed to the old DB plan, the mean conditional retirement probability was 0.44 . However, in 2001 , the first post-reform year for 63 -year-olds, it had dropped to 0.31. Apparently, this is a sharp decline. In 2003, there was a new decrease in the conditional retirement probability and from 2003 and onwards, the conditional retirement rates almost converged in the local government sector and the private sector.

Figure $2 b$ shows the evolution of conditional retirement rates of men who were married to women aged 63 in the local government sector and the private sector, respectively. From ocular inspection, we note that the two lines track each other surprisingly well. In 2002, there is a tiny relative decrease for men married to women employed in the private sector, but otherwise it is striking how close the lines are. One may notice that the level of the conditional retirement probability on average is higher for husbands than for wives. This can be explained by the fact that around $17 \%$ of the husbands are 65 years of age-65-year-olds have a retirement probability that is close to 1 . If one removes those who are aged over 64, the lines are still very parallel, even though the level of the conditional retirement probability is substantially lower. Moreover, the regression results reported in Sect. 7 are essentially unaffected.

For the difference-in-difference approach to be valid, the group-specific fixed effect should be the same across years - $\theta_{\text {LGW }}$ of Eq. (1) should be time invariant. Thus, we want the composition of the treatment and control groups to be unchanged by the 


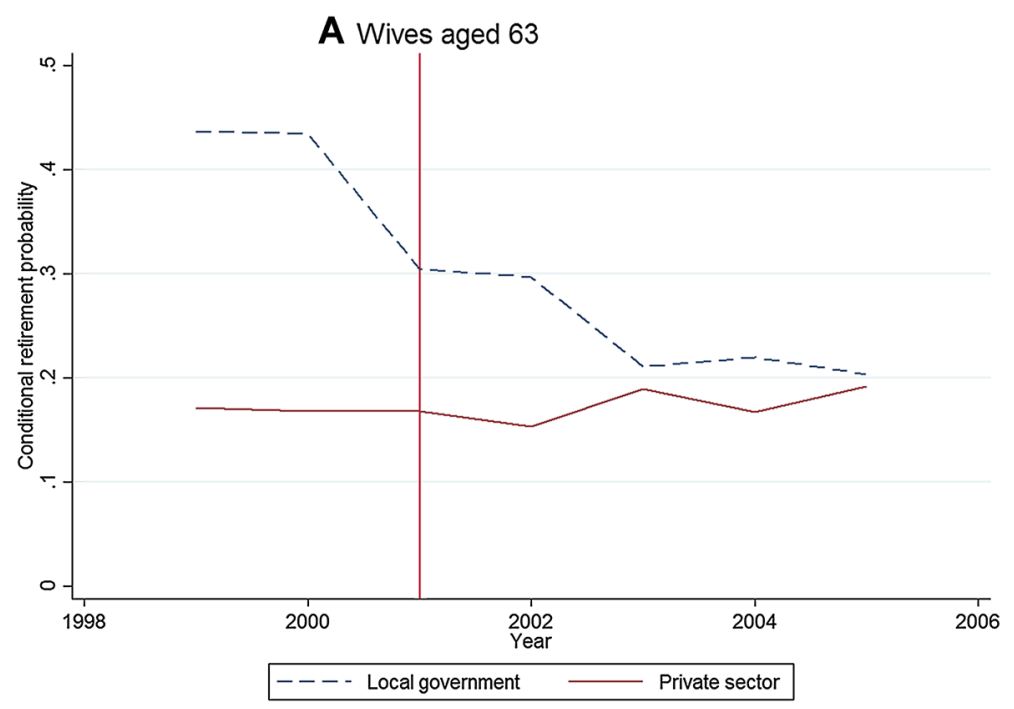

B Husbands married to wives aged 63

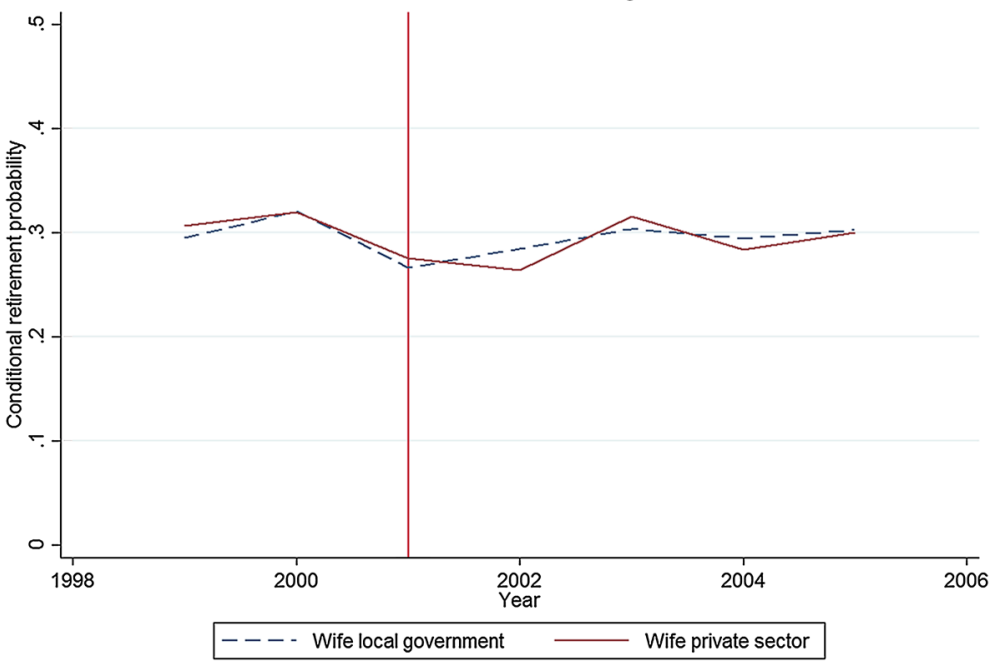

Fig. 2 Conditional mean retirement probabilities for 63-year-old wives and their husbands

reform. If there were a large response of 62-year-old women to the occupational reform, a duration model would be called for. ${ }^{15}$ Of particular interest is the fact that those who were aged 63 in 2001 were exposed to the new DC plan already in the year

\footnotetext{
15 At present, the empirical analysis includes individuals born 1936-1942. Since the untreated cohorts of 1936 and 1937 can only be traced back to 1998, the possibilities of conducting an interesting duration analysis are nonetheless limited here. See An et al. (2004) and Honoré and de Paula (2014) for duration models of joint retirement.
} 

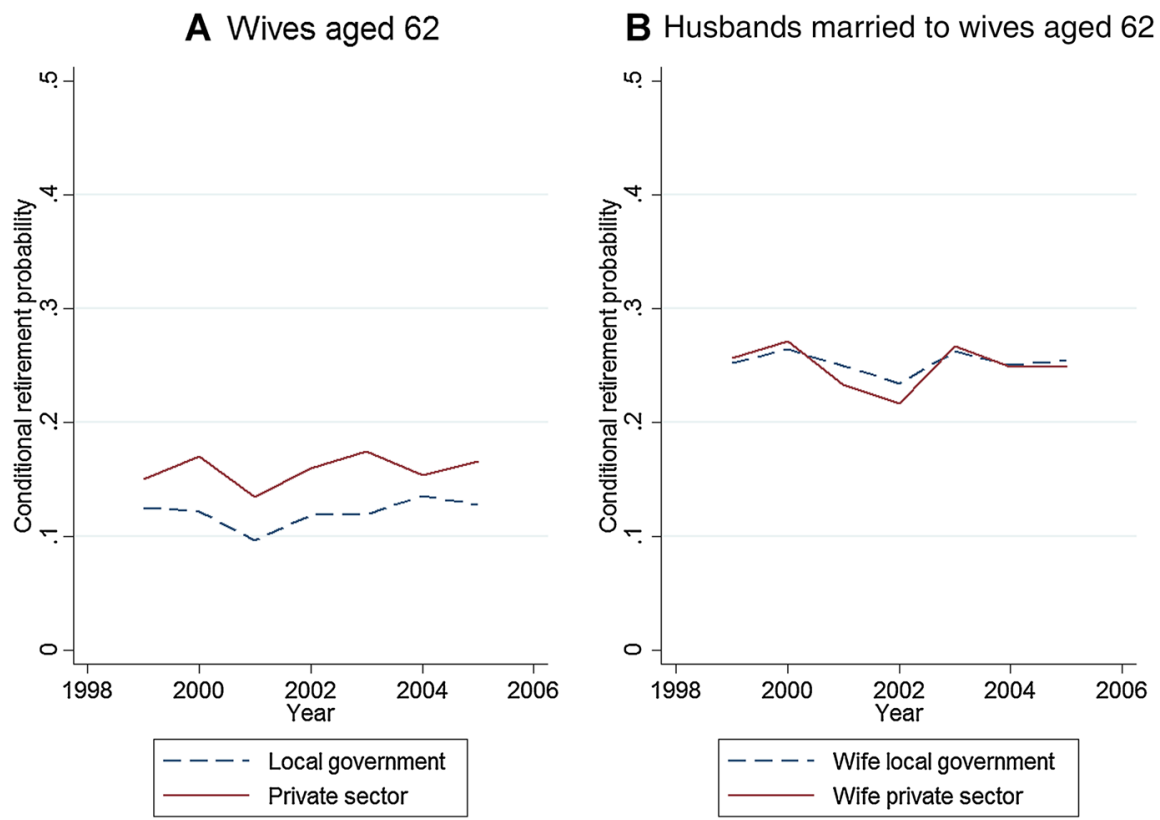

Fig. 3 Conditional mean retirement probabilities for 62-year-old wives and of husbands married to 62year-old wives, 1999-2005

2000 as 62 -year-olds. Table 1 shows that benefit accruals increased also for 62 -yearolds, even though the magnitude of the increase was substantially larger for 63-year-old local government workers. Figure $3 \mathrm{a}$ depicts the evolution of the retirement rate for 62 -year-old women, conditional on being part of the labor force as 61-year-olds. We see that the level is similar in 1999 and 2000 for 62-year-old female local government workers, whereas there was small increase for female private sector workers 19992000. Accordingly, there is no graphical evidence of a clear response of 62-year-old local government workers to the occupational pension reform. For other years, the lines in Fig. 3a are parallel, with 2004 and 2005 as exceptions. Figure $3 \mathrm{~b}$ reveals that the husbands' retirement probabilities in the two groups evolve in pretty much the same way.

Additional graphical evidence, which points in the same direction, is provided by the simple "survival graphs" of Fig. 4. Figure 4 plots the share of non-retired as a function of the wife's age for the 1937 pre-reform cohort and for the 1938-1940 postreform cohorts. ${ }^{16}$ We see that there was a massive reduction in retirement entries of 63 -year-old wives in the local government sector (panel A). Moreover, we see that the husbands' retirement probability went down similarly in both the treatment group and the control group (panel B). Figure 5 of Appendix 2 instead samples the husbands' birth cohorts and shows the fraction of non-retired as a function of the husband's age.

16 Since I have data from 1998 to 2005, I can follow the birth cohorts $1937-1940$ from age 61 to 65. 

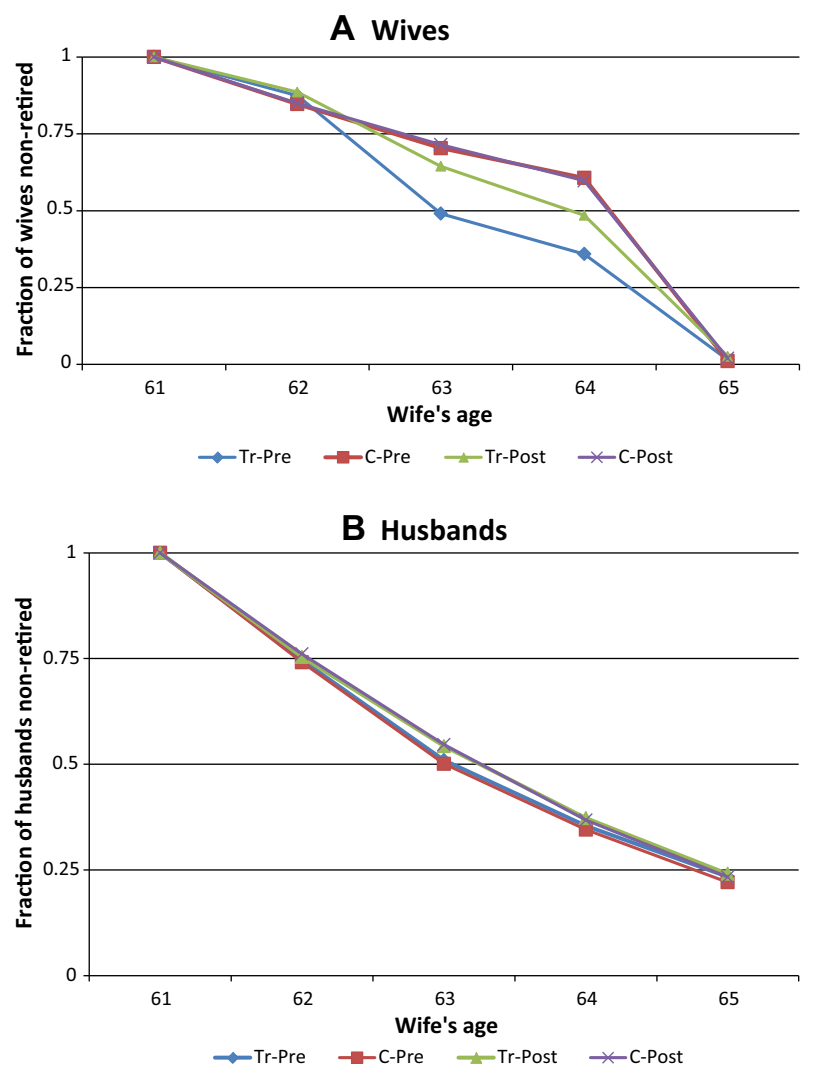

Fig. 4 Fraction of non-retired in the treatment (Tr)- and control (C) groups, by the wife's age. "Pre" refers to the 1937 birth cohort. "Post" refers to the 1938-1940 birth cohorts. The treatment (control) group consists of couples where the wife is in the local government sector (private sector) at age 61. Sample consists of couples where both spouses were in the labor force when the wife was aged 61

It is striking, both in Figs. 4 and 5, that there was a huge mass of retirement entries at age 65 , especially in the private sector.

\subsection{The correlation between the two spouses' retirement decisions}

Before turning to the regression analysis, it can be fruitful to examine the prevalence of joint retirement in Sweden. More specifically, we look at the correlation between the two spouses' retirement probability, conditional on that the two spouses were in the labor force in year $t-1$. Table 2 illustrates the correlation coefficient between the wife's retirement and the husband's retirement in the data 1999-2005 for the ages 60-65. In most cases, the retirement decision of spouses of age $s$ is most strongly correlated with the other spouse's retirement decision if the other spouse is also aged $s$. The italicized column of Table 2 is of special interest as it reflects a large subset of the estimation sample. In couples where both spouses are aged 63, the correlation coefficient is 0.19 . 
Table 2 Correlation coefficients for the husbands' and wives' retirement decisions

\begin{tabular}{|c|c|c|c|c|c|c|}
\hline & \multicolumn{6}{|c|}{ Wife's age } \\
\hline & 60 & 61 & 62 & 63 & 64 & 65 \\
\hline \multicolumn{7}{|c|}{ Husband's age } \\
\hline 60 & $\begin{array}{l}0.1785 \\
(8528)\end{array}$ & $\begin{array}{l}0.1005 \\
(4516)\end{array}$ & $\begin{array}{l}0.0853 \\
(2294)\end{array}$ & $\begin{array}{l}0.067 \\
(1141)\end{array}$ & $\begin{array}{l}0.0458 \\
(554)\end{array}$ & $\begin{array}{l}0.0786 \\
(273)\end{array}$ \\
\hline 61 & $\begin{array}{l}0.0882 \\
(9481)\end{array}$ & $\begin{array}{l}0.2225 \\
(6477)\end{array}$ & $\begin{array}{l}0.14 \\
(3348)\end{array}$ & $\begin{array}{l}0.0804 \\
(1686)\end{array}$ & $\begin{array}{l}0.0383 \\
(798)\end{array}$ & $\begin{array}{l}0.0972 \\
(377)\end{array}$ \\
\hline 62 & $\begin{array}{l}0.0964 \\
(8499)\end{array}$ & $\begin{array}{l}0.1752 \\
(6966)\end{array}$ & $\begin{array}{l}0.1867 \\
(4705)\end{array}$ & $\begin{array}{l}0.1394 \\
(2383)\end{array}$ & $\begin{array}{l}0.1963 \\
(1102)\end{array}$ & $\begin{array}{l}0.0218 \\
(558)\end{array}$ \\
\hline 63 & $\begin{array}{l}0.0798 \\
(6375)\end{array}$ & $\begin{array}{l}0.1228 \\
(6161)\end{array}$ & $\begin{array}{l}0.1693 \\
(5002)\end{array}$ & $\begin{array}{l}0.19 \\
(3157)\end{array}$ & $\begin{array}{l}0.1817 \\
(1498)\end{array}$ & $\begin{array}{l}0.004 \\
(724)\end{array}$ \\
\hline 64 & $\begin{array}{l}0.092 \\
(4292)\end{array}$ & $\begin{array}{l}0.1111 \\
(4620)\end{array}$ & $\begin{array}{l}0.1163 \\
(4318)\end{array}$ & $\begin{array}{l}0.1494 \\
(3350)\end{array}$ & $\begin{array}{l}0.2177 \\
(1914)\end{array}$ & $\begin{array}{l}0.0499 \\
(1028)\end{array}$ \\
\hline 65 & $\begin{array}{l}0.0399 \\
(2781)\end{array}$ & $\begin{array}{l}0.0246 \\
(3234)\end{array}$ & $\begin{array}{l}0.0269 \\
(3404)\end{array}$ & $\begin{array}{l}0.0384 \\
(3030)\end{array}$ & $\begin{array}{l}0.0229 \\
(2122)\end{array}$ & $\begin{array}{l}0.1586 \\
(1339)\end{array}$ \\
\hline
\end{tabular}

The table reports correlation coefficients for the husband's retirement and the wife's retirement, 1999-2005. The number of observations is in parenthesis. The sample is selected in the same way as the estimation sample, i.e., both spouses should be in the labor force year $t-1$, none of the spouses should be employed in the central government sector and the husband should not be employed in the local government sector. The italicized column reflects a subset of the estimation sample

\section{Regression results}

\subsection{The wives' own response}

The main purpose of this study is to examine the husbands' response to the pension reform in the local government sector. However, as a first step we examine the wives' own response to the shift in the occupational pension plan. Table 3 reports the estimated treatment effects from an OLS difference-in-difference regression, where the wife's retirement status is regressed on a constant, the treatment dummies, a dummy for the local government sector and a full set of year dummies. Columns (1)-(2) report a treatment effect that is assumed to be homogenous across the whole period 2001-2005. Using the notation of Eq. (1), the homogenous treatment effect is ITT $=\sum_{t=2001}^{2005} \frac{\beta_{t} N_{t}}{N_{\mathrm{PR}}}$, where $N_{\mathrm{PR}}$ is the total number of observations in the estimation sample 2001-2005. Thus, the treatment effect for all years is a weighted average of the year-specific estimated treatment effects.

In the specification without covariates, reported in column 1 of Table 3 , the estimate of the treatment effect is -0.202 . The heteroskedasticity robust standard error is rather small - the $95 \%$ confidence interval ranges from -0.246 to -0.157 . According to this estimate, the probability of withdrawing retirement benefits among 63-year-old wives, who were in the labor force as 62-year-olds, decreased by 20 percentage points in the local government sector relative to the private sector during the post-reform period. The same qualitative pattern was found by Glans (2009), even though he did not focus on 63 -year-olds. 
Table 3 Wife's retirement status

(1)

$-0.202$

$(0.021)^{* * * *}$

Treatment 2001-2005

$(0.021) * *$

Treatment 2001

Treatment 2002

Treatment 2003

Treatment 2004

Treatment 2005

Control variables

No

The regression sample consists of couples where the wife is 63 years old and where both spouses were employed in the previous year, 2000-2005. Linear probability model. The regression equation follows Eq. (1) in the main text. Robust standard errors are in parenthesis. * denotes significance at $10 \%, * *$ at $5 \%$ and $* * *$ at $1 \%$. The number of observations is 15,518. All regressions include an intercept, a dummy for the local government sector and a full set of year dummies. The control variables are 17 dummies for the husband's age, 5 dummies for the wife's level of education, 5 dummies for the husband's level of education, 20 region dummies and interactions between year dummies and educational dummies

If the treatment dummy is orthogonal to the error term, we expect the estimate of the treatment effect to be unaffected by the inclusion of control variables. Intuitively, if the addition of control variables has a large impact on the estimate, there might be some concern that unobserved characteristics are also correlated with the regressor of interest. Column (2) reports results from a regression where a large number of control variables have been added to the regression equation. Interestingly, the treatment effect estimate of column (2) is identical to the estimate reported in column (1). The robust standard error is, however, somewhat larger when the control variables are added.

When the estimated treatment effects are allowed to be heterogeneous across years (columns 3 and 4), it turns out that the response does indeed differ across post-treatment years. These results are, of course, fully consistent with Fig. 2a. In particular, the relative decrease in retirement rates in the local government sector-as compared to the pre-reform year 2000_-was considerably lower in 2001-2002 than in 2003-2005. The most plausible explanation for the decrease in the retirement hazard in the local government sector between 2002 and 2003 is that norms adjust slowly. In fact, delayed adjustments to policy changes in approximately the same age group in the USA have recently been documented by Gelber et al. (2013) in a different context.

Once more, the estimated treatment effects are fairly similar in the regressions with and without control variables. A $\chi^{2}$ test does not reject the null hypothesis that the coefficient vectors containing the 5 coefficient estimates reported in column (3) and column (4) are equal at any reasonable level of significance, the $p$ value being 0.82 . 
These results are in line with findings in a large body of literature that estimates the effect of the individual's own retirement incentives on the probability of retiring or the retirement hazard. In fact, recent studies that exploit policy discontinuities for identification (Liebman et al. 2009; Manoli and Weber 2011) indicate that females are more responsive than males at the retirement margin. The response in retirement entries should, of course, be viewed in relation to the magnitude of the incentive change. I have made back-of-the-envelope calculations of the elasticity of the retirement probability with respect to one minus the implicit tax rate, where I use information from Table 3 , column (4), and Table $1 .{ }^{17}$ The retirement elasticity with respect to one minus the implicit tax rate is -0.20 . Thus, even though the treatment effect is estimated to be -0.25 , the implied retirement elasticity is not terribly large; Manoli and Weber (2011) estimated retirement elasticities of 0.12 for men and 0.38 for women. The reason is that the change in the benefit accrual for 63-year-olds between 2000 and 2005 is huge. Since individual pension incentives cannot be calculated for each individual in the sample, this elasticity figure should, however, be seen as a rough approximation, and probably a lower bound, of the "true" elasticity.

\subsection{The husbands' response}

We now turn to the husbands' response, which is the main focus of the paper. The results for the husband's retirement status are displayed in Table 4. Again, columns (1)-(2) report a treatment effect that is assumed to be homogenous across the whole period 2001-2005. Interestingly, column (1) reports a treatment effect estimate which is not statistically distinct from 0 . The point estimate is -0.001 , and the heteroskedasticity robust standard error is approximately of the same magnitude as in the regressions for females, 0.022. When covariates are added (column 2), the point estimate of the treatment effect changes sign and becomes positive, but is still very small, 0.007 . The standard error of the point estimate is now reduced as the inclusion of covariates decreases the variance in the estimated residuals. The $95 \%$ confidence interval ranges from -0.028 to 0.041 . This result suggests that a change in the wife's pension incentive does not affect the retirement decision of the husband.

Columns (3)-(4) show the estimated year-specific treatment effects. None of these estimates are statistically different from 0 . I therefore conclude that the husbands of those wives who were affected by the occupational pension reform in the local government sector did not change their retirement behavior due to reform, despite the large response of the wives. This finding is surprising given the well-documented correlation in the timing of spouses' retirement decisions. As mentioned in the introduction,

17 The elasticity is defined as $\eta_{\text {retirement }}=\frac{\beta_{2005}}{\operatorname{RETIRED}_{2000}^{\mathrm{LGW}}-\mathrm{WIFE}} / \frac{\Delta\left(1-\tau^{\mathrm{LGW} \_ \text {WIFE}}\right)-\Delta\left(1-\tau^{\mathrm{PS}}{ }_{-} \mathrm{WIFE}^{\mathrm{L}}\right)}{\left(1-\tau_{2000}^{\mathrm{LGW}}{ }^{\mathrm{WIFE}}\right)}$, where RETIRED ${ }_{2000}^{\text {LGW_WIFE }}$ is the retirement probability of local government wives in year 2000 and $\tau$ is the implicit tax caused by the pension system. The implicit tax rate at age 63 is defined as minus the benefit accrual divided by annual earnings, i.e. $\tau=-\frac{\left\{E\left(W_{63} \mid r=s+1\right)-E\left(W_{63} \mid r=s\right)\right\}}{w h}$, where wh is earnings.

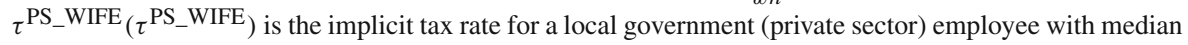
income. These quantities are reported in Table 1 . The mean retirement rate of 63 -year-old female local government workers was 0.44 in year 2000 . 
Table 4 Husband's retirement status

\begin{tabular}{|c|c|c|c|c|}
\hline & (1) & (2) & (3) & (4) \\
\hline Treatment 2001-2005 & $\begin{array}{l}-0.001 \\
(0.022)\end{array}$ & $\begin{array}{l}0.007 \\
(0.018)\end{array}$ & & \\
\hline Treatment 2001 & & & $\begin{array}{l}-0.011 \\
(0.029)\end{array}$ & $\begin{array}{l}0.011 \\
(0.021)\end{array}$ \\
\hline Treatment 2002 & & & $\begin{array}{l}0.018 \\
(0.028)\end{array}$ & $\begin{array}{l}0.012 \\
(0.021)\end{array}$ \\
\hline Treatment 2003 & & & $\begin{array}{l}-0.015 \\
(0.028)\end{array}$ & $\begin{array}{l}0.003 \\
(0.022)\end{array}$ \\
\hline Treatment 2004 & & & $\begin{array}{l}0.006 \\
(0.027)\end{array}$ & $\begin{array}{l}-0.000 \\
(0.021)\end{array}$ \\
\hline Treatment 2005 & & & $\begin{array}{l}-0.002 \\
(0.026)\end{array}$ & $\begin{array}{l}0.009 \\
(0.021)\end{array}$ \\
\hline Control variables & No & Yes & No & Yes \\
\hline
\end{tabular}

The regression sample consists of couples where the wife is 63 years old and where both spouses were employed in the previous year, 2000-2005. Linear probability model. The regression equation follows Eq. (1) in the main text. Robust standard errors are in parenthesis. *Significance at $10 \%$, ** at $5 \%$ and $* * *$ at $1 \%$. The number of observations is 15,518 . All regressions include an intercept, a dummy for the local government sector and a full set of year dummies. The control variables are 17 dummies for the husband's age, 5 dummies for the wife's level of education, 5 dummies for the husband's level of education, 20 region dummies and interactions between year dummies and educational dummies

these results do not point in the same direction as the results in, e.g., Zweimüller et al. (1996) and Coile (2004) who both find that husbands are sensitive to changes in their wives' incentives. In particular, Coile (2004) obtains cross-effects of wives' incentives on the husbands' retirement that are approximately as strong as the effects of the wives' incentives on the wives' own retirement. Cross-responses of that magnitude can be rejected here.

It is worth pointing out, however, that the results are consistent with small crossresponses between spouses; the upper limit of the $95 \%$ confidence interval for the female response is -0.157 and the corresponding lower limit for the husbands' response is -0.028 . Thus, cross-effects of approximately $1 / 5$ of the wives' response cannot be rejected (assuming complementarity). What do we know from other studies about the cross-effects between spouses? While comparisons with results obtained in the context of the standard static labor supply model should be made with great care, it can still be interesting to view these results in relation to the results obtained by Gelber (2014). Gelber estimated cross-effects for intensive margin earnings supply on Swedish administrative data for the years 1989-1991. He estimated a "compensated own elasticity" with respect to the own net-of-tax rate to be 0.25 for husbands and the "compensated cross-elasticity" with respect to the wife's net-of-tax rate to be 0.05 for 
Table 5 Placebo regressions

\begin{tabular}{llllll}
\hline & Wives & & & Husbands & \\
\cline { 2 - 3 } & $(1)$ & $(2)$ & & $(3)$ & 0.005 \\
Treatment 2000 & 0.003 & 0.015 & & 0.020 & $(0.023)$ \\
Control variables & $(0.029)$ & $(0.030)$ & & $(0.030)$ & Yes \\
\hline
\end{tabular}

The regression sample consists of couples where the wife is 63 years old and where both spouses were employed in the previous year, 1999-2000. Linear probability model. The regression equation follows Eq. (2) in the main text. Robust standard errors are in parenthesis. * Significance at $10 \%$, ** at $5 \%$ and $* * *$ at $1 \%$. The number of observations is 3,923. All regressions include an intercept, a dummy for the local government sector and a full set of year dummies. The control variables are 17 dummies for the husband's age, 5 dummies for the wife's level of education, 5 dummies for the husband's level of education, 20 region dummies and interactions between year dummies and educational dummies

husbands. This relatively modest cross-elasticity is not necessarily inconsistent with the results presented here. ${ }^{18}$

\subsection{Placebo tests}

Once more, the crucial identifying assumption is that the outcome variable would have evolved in the same way in the treated group (husbands married to wives in the local government sector) as in the non-treated group (husbands married to wives in the private sector) in the absence of a pension plan reform. To obtain a view on the validity of this identifying assumption, I will exploit the fact that our data set allows us to define the dependent variable also for 1999 , an earlier pre-reform year. The data set contains data for the years 1998-2005. But since we need to condition on labor force participation in the preceding year, we cannot include the retirement decision in 1998 in the analysis. We can perform "placebo-type" regressions where we assume that the pension plan reform instead affected the 1937 cohort (those who turned 63 in 2000), but not the 1936 cohort (those who turned 63 in 1999). In reality, both cohorts were unaffected by the reform. The following regression will be performed on data for 1999 and 2000:

$$
\begin{aligned}
& \operatorname{RETIRED}_{i g t}=\beta_{\text {placebo }}\left(\mathrm{LGW}_{g} \times \mathrm{YEAR}_{2000}\right)+\theta_{\mathrm{LGW}} \mathrm{LGW}_{g} \\
& +\mathrm{YEAR}_{2000}+\delta X_{i g t}+\varepsilon_{i g t}
\end{aligned}
$$

The placebo tests, with and without controls, are reported in columns (1)-(2) of Table 5 for wives and columns (3)-(4) of Table 5 for husbands. If the pre-reform trends were the same for the two groups, the coefficient for the interaction term in Eq. (2) should

\footnotetext{
18 Another caveat when comparing my study with Gelber (2014) is that he estimates compensated elasticities (as his econometric framework allows for income effects). In fact, the estimated uncompensated cross-response is insignificantly distinct from zero (see Table 3, column 1 of his paper). As emphasized in the theory section, my estimated treatment effect parameters are necessarily reduced form parameters capturing both potential complementarity effects and potential income effects. Moreover, since I study retirement decisions, the sample selections differ a lot.
} 
not be significantly distinct from 0 . From Table 5 , we can infer that it is indeed the case that the coefficients for the interaction term are close to zero (and very insignificant) for both wives and husbands. Thus, consistent with the graphical evidence provided in Fig. 2a the placebo estimates are close to zero for both wives and husbands.

\subsection{Further robustness checks and heterogeneity analysis}

One potential concern of the analysis is related to the dynamics of the retirement response. Two separate issues arise. First, in Sect. 4.2 we noted that retirement incentives for local government workers born in 1938 changed already when they were 62 years old. Thus, even though the graphical analysis did not indicate any substantial response of the 1938 cohort at the age of 62 , it is desirable to examine this further in a regression analysis.

Second, we cannot a priori rule out that husbands reacted to the change in the wives' incentives by retiring before the wife retires. In order to examine this hypothesis, I construct a new regression sample that includes all couples where both partners were in the labor force in period $t-2$. I then define a binary outcome variable that takes the value of 1 if the individual either retires in period $t$ or in $t-1$, assuming that retirement is an absorbing state. ${ }^{19}$ With these modifications, I run the same regressions defined by Eq. (1) above. I now allow for a response, both of husbands and wives, the year before the wife turns 63 . The number of observations increases from 15,518 to 21,793. It is now impossible to perform placebo tests as 1998 is the first year of data, and the sample is selected based on labor force status in year $t-2$.

Table 6, column (1), shows that the common treatment dummy, which now is estimated to be -0.208 , is very close to the treatment effect estimate in the main model, where the corresponding point estimate was -0.202 . The year-specific treatment effect estimates of column (2) are also close to those of column (4) of Table 3. The same holds true for the parameters reflecting the husbands' behavior. The treatment effect for 2001-2005 reported in column (3) is estimated to be 0.013 instead of 0.007 in the baseline model (column 2, Table 4).

Note that this exercise also serves as a robustness check of the way in which I select the regression sample. Until now I have defined the sample based on labor force status in year $t-1$. When running regressions with the standard binary outcome variable (which is 1 if the individual retires in period $t$ ) on the larger sample defined based on information in $t-2$, I obtain results that are similar (not reported).

It is also interesting to examine what happens if one instead uses an earnings-based outcome variable. In the analysis above, we defined an individual as being retired if he/she received a positive amount of pension income in year $t$. Since earnings will be positive, the year an individual retires an earnings-based definition necessarily needs to be based on earnings information as of year $t+1$. In what follows, I let the outcome variable take on the value of 1 in period $t$ if the individual had earnings below 1.75 price base amount in $t+1$. This cutoff limit was used by Glans (2009). The average male retirement rate in the sample now slightly falls from 0.29 to 0.25 . To achieve

19 Very few individuals in the sample make the transition from retirement to non-retirement. 
Table 6 Probability to retire in year $t$ or in year $t-1$

\begin{tabular}{lllll}
\hline & Wives & & & Husbands \\
\cline { 2 - 3 } & $(1)$ & $(2)$ & $(3)$ & $(4)$ \\
\hline Treatment 2001-2005 & -0.208 & & 0.013 & \\
Treatment 2001 & $(0.020)^{* * *}$ & & $(0.016)$ & 0.022 \\
Treatment 2002 & & -0.136 & $(0.020)$ \\
Treatment 2003 & $(0.026)^{* * *}$ & & 0.013 \\
Treatment 2004 & & -0.109 & $(0.020)$ \\
Treatment 2005 & $(0.026)^{* * *}$ & & 0.029 \\
& & -0.262 & $(0.020)$ \\
Control variables & & $(0.025)^{* * *}$ & & -0.005 \\
& & -0.257 & & $(0.020)$ \\
\hline
\end{tabular}

The regression sample consists of couples where the wife is 63 years old and where both spouses were employed in year $t-2,2000-2005$. The dependent variable is an indicator variable that takes on the value of 1 if the individual retired in year $t$ or $t-1$. Linear probability model. Robust standard errors are in parenthesis. $*$ Significance at $10 \%, * *$ at $5 \%$ and $* * *$ at $1 \%$. The number of observations is 21,793 . All regressions include an intercept, a dummy for the local government sector and a full set of year dummies. The control variables are 17 dummies for the husband's age, 5 dummies for the wife's level of education, 5 dummies for the husband's level of education, 20 region dummies and interactions between year dummies and educational dummies

comparability with the baseline results, I still define the regression sample in the same way as before. However, since the dependent variable now builds on information from period $t+1$ I will not be able to use data for 2005, the most recent year in the data set. It turns out that the results, which can be obtained upon request, are roughly similar to those in the main analysis.

If one instead sets the earnings cutoff limit to 0 , which is considerably less arbitrary, there is a dramatic drop in retirement rates in the sample. The average male retirement then falls from 0.29 to 0.12 . Accordingly, this retirement definition is very restrictive; it assigns some of those who we would consider as being genuine retirees to the working population. The regression results, which also can be provided upon request, are qualitatively similar to those in the main analysis. The female response is, however, approximately half as large as in the main analysis. Likewise, if I replace the dependent variable with log earnings I estimate very small and insignificant cross-responses.

I also examined different subgroups of the sample, where one perhaps may expect to estimate larger spillover effects. First, I examined a sample of couples where the age difference is small and the correlation in retirement decisions is larger (Table 2); husbands were aged 62, 63 and 64. Second, I estimated differential responses in couples with high and low within-couple earnings (in $t-1$ ) differentials. Third, I analyzed a sample where the wife earns the highest income (in $t-1)$ in the couple. Fourth, I studied a subsample with children in the household. Fifth, I separately studied couples 
where the wife had an educational degree for which the male share with that degree was very low (less than $10 \%$ ). In none of these cases, I estimated significant responses of the husband.

\section{Concluding discussion}

In a difference-in-difference setup, I have estimated own and cross-responses to an occupational pension reform affecting women in the local government sector born in 1938 and onwards. I provide clean graphical evidence that the retirement probability of 63-year-old wives in the local government sector decreased in the years after the reform. Seen over the whole post-reform period 2001-2005, the decrease relative to 2000 was 20 percentage points. However, a surprisingly robust finding is that there is no significant response of husbands. In the most preferred model, which includes a full set of control variables, the point estimate of the treatment effect is 0.007 . The $95 \%$ confidence interval ranges from -0.028 to 0.041 . Accordingly, large cross-responses for husbands can be ruled out. This suggests that cross-effects (from wives to husbands) are substantially smaller than the direct effect of the wife's own incentive on the wife's retirement. A caveat of the design is, however, that the number of available pre-reform years is limited.

How to explain the non-response of husbands? I would like to point at two factors: the age-composition of the sample and the norm to retire at age 65 . In practice, due to the nature of the reform, couples studied in this paper either exhibit small age differences or are couples where the husband is younger than the wife. If husbands married to younger wives are more responsive than husbands married to wives who are older or of the same age, spillover effects are more likely to be found when reforming pension incentives for women at somewhat younger ages.

It is also important to consider the role of bunching at certain retirement ages. The reform for local government workers implied that a large number of retirement entries moved from 63 to 65 . Both before and after the reform, a very large fraction of private sector employees retired at 65 . The strong norm to retire at 65 may attenuate cross-responses.

Acknowledgements This paper has benefited from comments and valuable suggestions from two anonymous referees, Spencer Bastani, Sören Blomquist, Daniel Hallberg, Che-Yuan Liang, Laurent Simula and seminar participants at Uppsala University and the IIPF Congress. Financial support from the Jan Wallander and Tom Hedelius Foundation and the Uppsala Center for Fiscal Studies is also gratefully acknowledged.

Open Access This article is distributed under the terms of the Creative Commons Attribution 4.0 International License (http://creativecommons.org/licenses/by/4.0/), which permits unrestricted use, distribution, and reproduction in any medium, provided you give appropriate credit to the original author(s) and the source, provide a link to the Creative Commons license, and indicate if changes were made.

\section{Appendix 1: Summary statistics}

See Table 7. 
Table 7 Summary statistics for the regression sample

\begin{tabular}{|c|c|c|c|c|}
\hline & \multicolumn{2}{|c|}{ Pre-reform, 1999-2000 } & \multicolumn{2}{|c|}{ Post-reform, 2001-2005 } \\
\hline & Local government & Private & Local government & Private \\
\hline \multirow[t]{2}{*}{ Husband retired } & 0.31 & 0.31 & 0.29 & 0.29 \\
\hline & $(0.46)$ & $(0.46)$ & $(0.46)$ & $(0.45)$ \\
\hline \multirow[t]{2}{*}{ Wife retired } & 0.44 & 0.17 & 0.24 & 0.18 \\
\hline & $(0.50)$ & $(0.38)$ & $(0.43)$ & $(0.38)$ \\
\hline \multirow[t]{2}{*}{ Husband's age } & 62.10 & 62.21 & 62.12 & 62.07 \\
\hline & $(2.82)$ & $(2.87)$ & $(2.80)$ & $(2.93)$ \\
\hline \multirow[t]{2}{*}{ Wife high school } & 0.42 & 0.34 & 0.44 & 0.38 \\
\hline & $(0.49)$ & $(0.47)$ & $(0.50)$ & $(0.49)$ \\
\hline \multirow[t]{2}{*}{ Wife university } & 0.28 & 0.09 & 0.33 & 0.13 \\
\hline & $(0.45)$ & $(0.29)$ & $(0.47)$ & $(0.34)$ \\
\hline \multirow[t]{2}{*}{ Husband high school } & 0.41 & 0.39 & 0.44 & 0.43 \\
\hline & $(0.49)$ & $(0.49)$ & $(0.50)$ & $(0.49)$ \\
\hline \multirow[t]{2}{*}{ Husband university } & 0.16 & 0.14 & 0.18 & 0.16 \\
\hline & $(0.37)$ & $(0.34)$ & $(0.38)$ & $(0.36)$ \\
\hline Observations & 1779 & 2144 & 6523 & 6985 \\
\hline
\end{tabular}

Note that "the regression sample" both includes the 2000-2005 sample and the 1999 sample, which is used in the placebo test

\section{Appendix 2: Survival graph for husbands}

\section{See Fig. 5.}

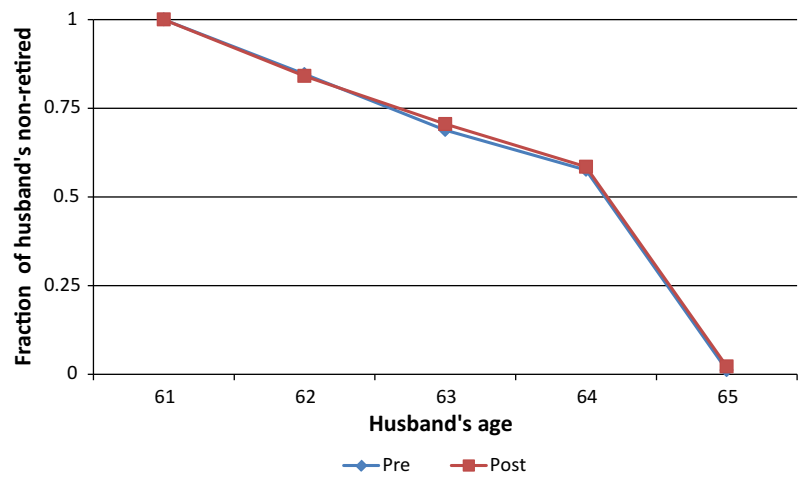

Fig. 5 Fraction of non-retired husbands in pre- and post-reform cohorts. "Pre" refers to the 1937 birth cohort. "Post" refers to the 1938-1940 birth cohorts. At age 61, husbands were employed in the private sector and married to a wife who was also in the labor force 


\section{Appendix 3: The occupational pension system for local government work- ers}

As described in Sect. 4.2, the pension plan for local government workers that was in place prior to 2000, PA-KL, stipulated that the sum of the public pension benefit (PB) and the occupational pension benefit (OB) should be equal to a certain fraction, $\zeta$, of the individual's qualifying income (QI). Thus, the OB was determined as a residual amount:

$$
\mathrm{TB}=\zeta \times \mathrm{QI}=\mathrm{PB}+\mathrm{OB}
$$

where TB denotes the total annual pension benefit. The local government worker was eligible for full pension benefits given that he/she had reached the retirement age and had worked at least 30 years since the age of 28 in the sector. The QI was defined as an average of the five best earnings years out of the of the seven most recent earnings years. Table 8 shows the replacement rate $\zeta$ as a function of the qualifying income, QI.

The level of the public pension benefit, PB, was determined in the following way

$$
\mathrm{PB}=\underbrace{0.6 \times \mathrm{APP} \times \min \left(\frac{N_{\mathrm{PP}}}{30}, 1\right)}_{\text {Supplementary pension }\left({ }^{\mathrm{ATP}}{ }^{\prime}\right)}+\underbrace{\omega \times B A}_{\text {Basic pension }}
$$

where APP is the average pension points earned during the 15 years with the highest earnings. At maximum, the individual could earn 6.5 pension points each year. 1 pension point amounted to 1 price base amount, BA. $N_{\mathrm{PP}}$ is the number of years for which the individual earned pension points. $\omega$ is a parameter that determines the level the basic pension. $\omega$ was $96 \%$ for singles and $78.5 \%$ for married individuals. $^{20}$

Early withdrawals before the retirement age could be made from the age of 60 under the PA-KL agreement. Early retirement was subject to a penalty. Table 9 shows the monthly adjustment of the gross pension benefit (TB) in percent. Suppose that the employee, under the old agreement, was subject to the 63-to-65 rule, i.e., she was eligible for full pension benefits by the month she turned 63. If she withdrew pension benefits already from the month she turned 60 , the gross pension benefit was reduced by

$$
12 \times 0.5 \%+12 \times 0.45 \%+12 \times 0.35 \%=15.6 \% \text {. }
$$

Note, however, that the individual was unaffected by the early-withdrawal penalty in the public pension system.

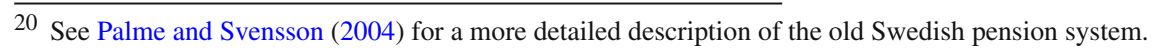


Table 8 Formula for gross pension in the public sector

\begin{tabular}{lll}
\hline $\begin{array}{l}\text { Qualifying income } \\
\text { QI) }\end{array}$ & $\begin{array}{l}\text { Total gross replacement } \\
\text { rate in the interval }\end{array}$ & $\begin{array}{l}\text { Total gross replacement rate at } \\
\text { the upper end of the interval, } \zeta\end{array}$ \\
\hline $0-1$ BA & $96 \%$ & $96 \%$ \\
1 BA-2.5 BA & $78.5 \%$ & $85.5 \%$ \\
2.5 BA-3.5 BA & $60 \%$ & $78.2 \%$ \\
3.5 BA-7.5 BA & $64 \%$ & $70.6 \%$ \\
7.5 BA-20 BA & $65 \%$ & $67.1 \%$ \\
20 BA-30 BA & $32.5 \%$ & $55.6 \%$ \\
30 BA- & 0 & - \\
\hline
\end{tabular}

BA, price base amount. In 2010 BA is SEK 42,400 (approximately EUR 4700). 1 USD $\approx 7$ SEK

Table 9 Adjustments for early/late withdrawals (in \% of gross pension) under PA-KL

\begin{tabular}{llllllll}
\hline Age & 60 & 61 & 62 & 63 & 64 & 65 & 66 \\
\hline Retirement age 65 & -0.5 & -0.5 & -0.4 & -0.3 & -0.3 & 0.1 & 0.1 \\
Retirement age 63-65 & -0.5 & -0.45 & -0.35 & 0 & 0 & 0.1 & 0.1 \\
\hline
\end{tabular}

\section{References}

Ai, C., \& Norton, E. C. (2003). Interaction terms in logit and probit models. Economics Letters, 80, 123-129. An, M. Y., Christensen, B. J., \& Gupta, N. D. (2004). Multivariate mixed proportional hazard modelling of the joint retirement of married couples. Journal of Applied Econometrics, 19, 687-704.

Atalay, K., \& Barrett, G. (2015). Pension incentives and the retirement decisions of couples. Working paper, August 2015.

Baker, M. (2002). The retirement behavior of married couples. Evidence from the spouse's allowance. Journal of Human Resources, 37(1), 1-34.

Blau, D. M. (1998). Labor force dynamics of married couples. Journal of Labor Economics, 16(3), 595-629.

Brown, K. M. (2013). The link between pensions and retirement timing: Lessons from California teachers. Journal of Public Economics, 98, 1-14.

Burtless, G. (1986). Social security, unanticipated benefit increases, and the timing of retirement. The Review of Economic Studies, 53(5), 781-805.

Coile, C. (2004). Retirement incentives and couples' retirement decisions. Topics in Economic Analysis \& Policy, 4(1), 1-30.

Cribb, J., Emmerson C., \& Tetlow, G. (2013). Incentives, shocks or signals: Labour supply effects of increasing the female state pension age in the UK. IFS working papers W13/03, Institute for Fiscal Studies.

Gelber, A. M. (2014). Taxation and the earnings of husbands and wives: Evidence from Sweden. Review of Economics and Statistics, 96(2), 287-305.

Gelber, A. M., Jones, D., \& Sacks, D. W. (2013). Earnings adjustment frictions: Evidence from the social security earnings test. National Bureau of Economic Research working paper series, no. 19491.

Gerard, F., \& Nekby, L. (2012). Spousal joint retirement: A reform based approach to identifying spillover effects. Unpublished manuscript.

Glans, E. (Ed.). (2009). From defined benefit to defined contribution - The effect of an occupational pension reform on retirement behaviour. In Pension Reforms and Retirement Behaviour (Thesis). Economic Studies 118. Department of Economics, Uppsala University.

Gustman, A. L., \& Steinmeier, T. L. (2000). Retirement in dual-career families: A structural model. Journal of Labor Economics, 18(3), 503-545. 
Gustman, A. L., \& Steinmeier, T. L. (2004). Social security, pensions and retirement behaviour within the family. Journal of Applied Econometrics, 19, 723-737.

Hagen, J. (2016). What are the health effects of postponing retirement? An instrumental variable approach. IFAU working paper 2016:11.

Hallberg, D. (2011). Economic fluctuations and retirement of older employees. Labour, 25(3), 287-307.

Harnæs, E., Jia, Z., \& Strøm, S. (2006). Retirement in non-cooperative families. Memorandum No 15/2006. Department of Economics, University of Oslo.

Honoré, B. E., \& de Paula, A. (2014). Interdependent durations in joint retirement. Cemmap working paper CWP08/14.

Hurd, M. D. (1990). The joint retirement decision of husbands and wives. In D. A. Wise (Ed.), Issues in the economics of aging. Chicago: University of Chicago Press.

Johnsen, J. V., \& Vaage, K. (2015) Spouses' retirement and the take-up of disability pension. No 03/15, Working Papers in Economics, University of Bergen, Department of Economics.

Kapur, K., \& Rogowski, J. (2007). The role of health insurance in joint retirement among married couples. Industrial and Labor Relations Review, 60(3), 397-407.

Karlström, A., Palme, M., \& Svensson, I. (2011). Assessing the welfare change from a pension reform. International Tax and Public Finance, 18(6), 634-657.

Laun, T., \& Wallenius, J. (2015). A life cycle model of health and retirement: The case of Swedish pension reform. Journal of Public Economics, 127, 127-136.

Liebman, J. B., Luttmer, E. F. P., \& Seif, D. G. (2009). Labor supply responses to marginal Social Security benefits: Evidence from discontinuities. Journal of Public Economics, 93, 1208-1223.

Manoli, D, \& Weber, A. (2011). Nonparametric evidence on the effects of financial incentives on retirement decisions. NBER working paper no. 17320.

Mastrogiacomo, M., Alessie, R., \& Lindeboom, M. (2004). Retirement behavior of Dutch elderly households. Diversity in retirement patterns across different household types. Journal of Applied Econometrics, 19(6), 777-793.

Michaud, P., \& Vermeulen, F. (2011). A collective labor supply model with complementarities in leisure: Identification and estimation by means of panel data. Labour Economics, 18, 159-167.

Palme, M., \& Svensson, I. (2004). Income security programs and retirement in Sweden. In J. Gruber \& D. Wise (Eds.), Social security and retirement around the world: Microestimation. Chicago: University of Chicago Press.

Schirle, T. (2008). Why have the labor force participation rates of older men increased since the mid-1990's? Journal of Labor Economics, 26(4), 549-594.

Selin, H. (2011). What happens to the husband's retirement decision when the wife's retirement incentives change? Uppsala Center for Fiscal Studies working paper 2011:8.

Stancanelli, E. (2012) Spouses' retirement and hours outcomes: Evidence from twofold regression discontinuity with difference-in-difference. IZA discussion paper no. 6791.

Sundén, A. (2006). The Swedish experience with pension reform. Oxford Review of Economic Policy, 22(1), 133-148.

Vermeulen, F. (2002). Collective household models: Principles and main results. Journal of Economic Surveys, 16, 533-564.

Zweimüller, J., Winter-Ebmer, R., \& Falkinger, J. (1996). Retirement of spouses and social security reform. European Economic Review, 40, 449-472. 